\title{
Iões Metálicos em Medicina: Do Diagnóstico à Terapia
}

\author{
M. Amélia Santos \\ Centro de Química Estrutural, Instituto Superior Técnico, \\ Universidade de Lisboa \\ masantos@ist.utl.pt
}

\begin{abstract}
Assim como a natureza usa metais em sistemas biológicos, também os químicos se aliaram à Medicina na descoberta de medicamentos cujo mecanismo de acção está associado a uma interacção (coordenação) com iões metálicos, de que resultou a Química Inorgânica Medicinal. As suas aplicações dividem-se em duas classes principais: a dos fármacos como compostos orgânicos (ligandos) cuja acção resulta da sua coordenação com iões metálicos existentes no organismo, não ligados ou ligados a proteínas; a dos fármacos como complexos de metais (metalofármacos), cuja resposta clínica depende intrinsecamente do metal, e que são usados na terapia ou no diagnóstico de doenças. Serão aqui apresentados exemplos representativos destas duas classes de fármacos em uso clínico, seguido de uma referência genérica às suas propriedades mais relevantes. Por fim apresenta-se uma selecção de exemplos de resultados recentes em desenvolvimento.
\end{abstract}

\section{INTRODUÇÃO}

A Química Inorgânica Medicinal é uma área recente da Química Medicinal que tem dado uma importante contribuição no design e desenvolvimento de novos fármacos para uso na terapia e no diagnóstico de doenças. Com efeito, muitos iões metálicos têm um papel crucial em processos biológicos e biomédicos, devido à sua interaç̧ão com proteínas e com o DNA. Assim, a actividade farmacológica de muitos compostos orgânicos resulta da sua coordenação com iões metálicos existentes em sistemas biológicos, nomeadamente como inibidores de metaloenzimas, enquanto outros podem interferir em metabolismos patológicos associados a iões metálicos no organismo e corrigir distorções homeostáticas localizadas ou genéricas, provocadas por factores genéticos ou ambientais. Por outro lado, mimetizando a natureza que usa metais em sistemas biológicos, o Homem também tem usado iões metálicos essenciais como nutrientes (ex. ferro como Ferrochel ${ }^{\circledR}$, bisglicinato de $\mathrm{Fe}(\mathrm{II})$ ), muito embora a selecção do meio transportador e o controle rigoroso da dosagem sejam muito importantes pois o limite entre a essencialidade e a toxicidade (o bom e o mau) pode ser muito estreito. Contudo, verifica-se que, desde há cerca de um século, a maior aplicação dos compostos inorgânicos em Medicina, tem estado associada ao seu uso como componentes de agentes de diagnóstico e de terapia (metalofármacos) para estudar e tratar uma variedade de doenças e desordens metabólicas. Nestes casos, uma vez que a maior parte dos metais neles envolvidos não são essenciais e podem ser tóxicos, o papel do químico no design destes metalofármacos é fundamental para "embrulhar" ou "dar asas" ao metal de modo a garantir o melhor balanço possível entre o impacto positivo da sua acção de terapia ou diagnóstico de doenças e a sua potencial toxicidade.

Na Figura 1 estão esquematicamente representados alguns exemplos de áreas de aplicação da química inorgânica medicinal, sendo subsequentemente descritos, nas respectivas secções, alguns exemplos representativos dessas aplicações.

\section{Correcção de metals essencials ou IntRusos - Agen- TES DE QUELAÇÃo}

Muito embora o corpo humano contenha cerca de 50 elementos, apenas cerca de metade destes são essenciais ou

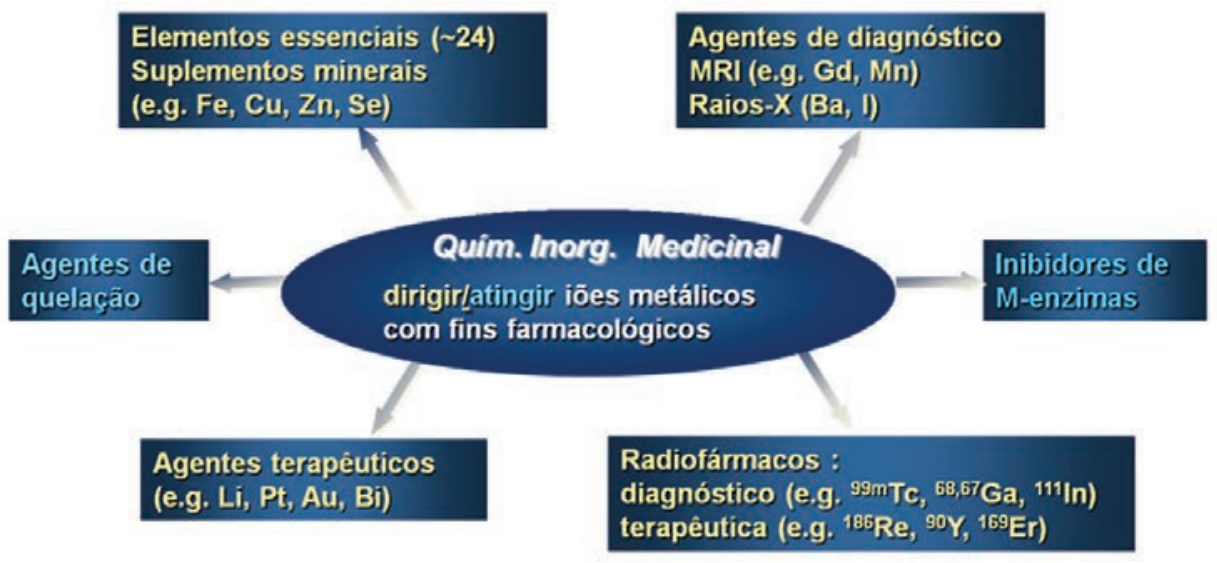

Figura 1 - Metais em Medicina: diagnóstico, terapia e alvo (adaptado da ref. [1]) 
benéficos para a vida, enquanto a outra parte é introduzida por meios exteriores (intencional ou acidentalmente). Os que existem em quantidades vestigiais são de particular importância, muito embora tanto a sua deficiência como o seu excesso possam conduzir a situações patológicas graves (Tabela 1).

$\mathrm{Na}$ verdade, vestígios de metais não essenciais podem atingir níveis de elevada toxicidade, ou por competirem com outros metais essenciais por certos centros ligantes biológicos ( $\mathrm{Hg}, \mathrm{Al})$, ou ainda por serem radioactivos $(\mathrm{Pu})$ e/ou genotóxicos (Cr(VI)). Por outro lado, o excesso e a acumulação de certos metais essenciais no organismo podem derivar de alterações genéticas (Fe, $\mathrm{Cu}$ ). No caso do ferro, a sua sobrecarga pode dever-se à hemocromatose ou à hemossiderose (sobrecarga de Fe decorrente do tratamento da sua deficiência hereditária, $\beta$-talassemia); o excesso de cobre pode estar associado à doença de Wilson. Estes iões metálicos são redox-activos e, quando na sua forma livre (não ligados a biomoléculas), podem gerar espécies reactivas de oxigénio (stresse oxidativo), pelo que a sua acumulação em certos órgãos pode gerar processos inflamatórios e degenerativos e levar à falência de órgãos vitais (ex. fígado, coração e cérebro).

Para solucionar problemas de acumulação sistémica de iões metálicos ou de desregulação da sua homeostase em certos órgãos, recorre-se normalmente ao uso de fármacos para actuar em terapias de quelação. Este tipo de compostos (quelantes) deverá ter elevada afinidade e especificidade para certos iões metálicos, actuando no nosso corpo como aves de rapina com as suas garras, possibilitando assim a sua sequestração e remoção do organismo.

O chumbo $(\mathrm{Pb})$ foi um dos primeiros metais a serem removidos de organismos intoxicados por tratamento clínico com agentes de quelação. Muito embora o mais antigo e mais comum tratamento se tenha baseado na administração de EDTA (ácido etilenodiaminotetraacético) ou respectivos sais, a falta de especificidade deste ligando para o $\mathrm{Pb}$ tem limitado a sua aplicabilidade, levando assim à pesquisa e desenvolvimento de novos ligandos com vista a melhoramento desta e de outras propriedades importantes dos fármacos, nomeadamente da razão benefício/toxicidade.

\subsection{Agentes quelantes DE FERRO}

Como exemplo representativo de iões metálicos essenciais que podem atingir níveis descontrolados de concentração no corpo humano e com necessidade de intervenção médica, o ferro assume um papel relevante. De facto, apesar de ser um elemento essencial para um funcionamento adequado das células vivas, o ferro tem de ser mantido dentro de um certo nível (200-1500 mg) no corpo humano, pois quando em excesso torna-se muito tóxico. Excessos de ferro podem ocorrer sistemicamente (principalmente em órgãos parenquimatosos) ou localmente (ex. tecidos isquémicos, cérebros de pacientes com doenças neurodegenerativas). As doenças associadas à desregulação sistémica do ferro no corpo humano são maioritariamente de origem genética, podendo revelar-se como uma sobrecarga (hematocromatose) ou uma deficiência ( $\beta$-talassemia) [3]. Contudo, ironicamente, o tratamento desta deficiência, envolvendo normalmente transfusões intensivas de sangue, resulta frequentemente num excesso de ferro (hemossiderose). Assim, ambas estas desordens sistémicas de Fe têm como consequência situações de sobrecarga de ferro, por ausência de mecanismos eficientes para a sua excreção. Como na sua forma livre (não ligado a proteínas) o Fe é extremamente tóxico, podendo gerar espécies reactivas de oxigénio, a sua acumulação em certos órgãos pode promover processos inflamatórios e degenerativos, levando à falência de órgãos

Tabela 1 - Importância da homeostase de metais essenciais (exemplos)

\begin{tabular}{|c|c|c|}
\hline \multirow{2}{*}{ Metal } & \multicolumn{2}{|c|}{ Doença ou Perturbação } \\
\hline & deficiência & excesso \\
\hline $\mathrm{Ca}$ & Enfraquecimento de ossos & Calcificação de cartilagens; cálculos renais \\
\hline Co & Anemia; anorexia; degenerescência medular & Cardiomiopatia; anorexia \\
\hline $\mathrm{Cu}$ & Anemia; pigmentação deficiente & Doença de Wilson; cirrose hepática \\
\hline $\mathrm{Cr}$ & Alteração do metabolismo da glucose; diabetes & Carcinogénico no estado de oxidação VI \\
\hline $\mathrm{Fe}$ & Anemia; $\beta$-talassemia & Hemocromatose; hemossiderose; falhas cardíacas \\
\hline $\mathrm{Mg}$ & Hiperirritabilidade neuromuscular & Diarreia; depressão do SNC e Periférico \\
\hline $\mathrm{Ni}$ & Mortalidade perinatal & Dermites de contacto; carcinoma de pulmão \\
\hline $\mathrm{Se}^{*}$ & Esterilidade; artrite crónica; queda cabelo & Problemas de visão; cambaleio cego \\
\hline $\mathrm{Si}^{*}$ & Deformações ósseas; defeitos cartilagens & Silicose \\
\hline $\mathrm{Zn}$ & Anorexia; raquitismo; alopécia; não cicatrização & Febre dos fumos metálicos \\
\hline
\end{tabular}

Adaptado da ref. [2]; * elemento não metálico 
vitais (ex. fígado, coração e cérebro). O tratamento clínico de sobrecarga crónica de ferro requer terapia de quelação, recorrendo a fármacos disponíveis comercialmente. Estes agentes de quelação são compostos orgânicos (ligandos) contendo entre um e três grupos quelantes ("garras") com elevada capacidade para se ligarem ao ião metálico e o sequestrarem (ver Figura 2). Desferral ${ }^{\circledR}$ (DFO) foi o primeiro agente de terapia de quelação do ferro e tem sido usado extensamente em hematologia há mais de 40 anos. O facto deste ligando apresentar hexadenticidade, fornecida por três grupos quelantes hidroxamato $(-\mathrm{CONHOH})$, justifica a sua elevada capacidade para complexar e sequestrar o ferro. Contudo, a sua inactividade oral e problemas colaterais (ex. difícil administração, elevado preço e baixa biodisponibilidade) levaram à subsequente necessidade de descoberta de outros agentes quelantes, nomeadamente a Desferiprona (DFP, ligando bidentado com um grupo quelante hidroxipirinona, aprovado em 1999) e o Desferasirox (ICL670, ligando tridentado com dois grupos quelantes adjacentes pirazol-bisfenolato, aprovado em 2005) [4]. Na Figura 2-B estão representadas a estrutura e estequiometria dos complexos $\left(\mathrm{FeL}_{\mathrm{n}}\right)$ que cada um destes agentes quelantes forma com o ião $\mathrm{Fe}^{3+}$. O número $(n)$ de moléculas de ligando necessárias, para assegurar uma eficiente complexação e sequestração do ião metálico (número de coordenação 6), varia ( $n=1-3$ ) de acordo com número de grupos quelantes ("garras”) que cada ligando possui (3-1, respectivamente). Apesar destes agentes terapêuticos de quelação serem maioritariamente administrados em protocolos simples (mono-fármaco), mais recentemente, eles têm também sido usados em combinação (poli-fármacos) para aumentar a acessibilidade a diferentes compartimentos celulares [5].

Contudo, é de realçar o facto dos novos agentes de terapia de quelação de ferro também não estarem isentos de problemas colaterais, como os associados à exigência de elevadas dosagens para compensar efeitos de diluição (DFP) ou à toxicidade hepatobiliar (ICL670). Assim, temos assis- tido a uma contínuo interesse na pesquisa de novos agentes quelantes para tratamento de doenças de sobredosagem crónica de ferro no sangue [6].

De referir que alguns quelantes de ferro, incluindo DFO, DFP e derivados análogos, têm também sido usados como fármacos (antídotos) na depuração de excesso de outros metais, com analogias químicas ao ferro (ex. Al, actinídeos) que, devido a uma contaminação externa (ambiental) se podem acumular no organismo e produzir situações graves de neuro- e geno-toxicidade) [7]. Por outro lado, agentes quelantes de ferro e de outros metais têm ainda sido usados para a passivação ou neutralização de metabolismos que envolvem o ferro ou outros biometais, promovendo assim a desactivação de desordens patológicos em que eles estão envolvidos (vide infra Figura 7) [8,9].

\section{INIBIDORES DE METALOENZIMAS}

Existem vários tipos de metaloenzimas contendo um ião metálico (ex.: Zn, Fe, Ni, Mo) no centro catalítico, as quais podem interferir em diversos processos fisiológicos ou patológicos. $\mathrm{O} \mathrm{Zn}^{2+}$ é um dos iões mais comuns em cofactores enzimáticos, nomeadamente nas metaloproteinases matriciais (MMP) e nas anidrases carbónicas (CA), as quais são, respectivamente, responsáveis pela degradação de tecido conjuntivo e pela regulação do $\mathrm{pH}$ no nosso organismo, podendo actuar no mesmo processo patológico como no desenvolvimento de tumores cancerígenos que proliferam em meio ácido e hipóxido [10]. Em condições normais, essas metaloenzimas podem ser responsáveis por processos fisiológicos importantes, sendo a sua actividade regulada e controlada por inibidores endógenos. Contudo, em condições anormais, poderá existir um descontrolo e hiper-produção destas enzimas, que assumem um papel decisivo no desenvolvimento e progressão de processos patológicos e inflamatórios graves (ex. cancro, artrites, periodontites, glaucoma). O uso de um composto
A

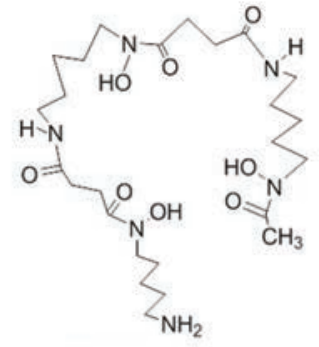

DFO, Desferrioxamina-B (Desferal ${ }^{\oplus}$ )

B

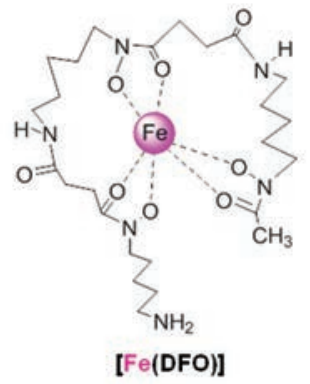

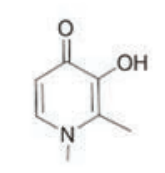

DFP. Desferiprona

(Ferriprox ${ }^{\circledast}$ )

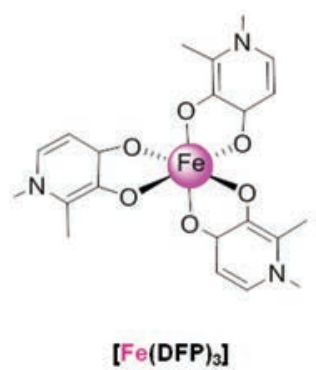

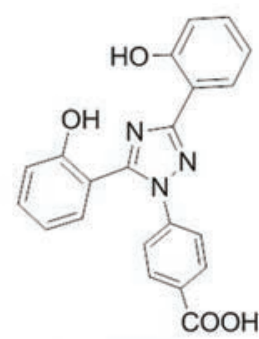

ICL670, Deferasirox (Exjade')

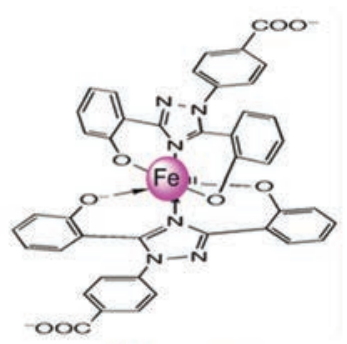

[Fe(ICL670 $\left.)_{2}\right]$

Figura 2 - Estrutura de agentes quelantes de ferro em uso clínico (nome comum e comercial) (A); estrutura dos correspondente complexos de Fe(III) (B) 
orgânico capaz de interactuar com uma enzima específica de um substrato e diminuir a sua actividade nefasta pode, portanto, originar uma resposta clínica. A actividade destes fármacos (ligandos) envolve a sua coordenação ao ião metálico do cofactor enzimático, pelo que os inibidores de metaloenzimas são também considerados alvos importantes no desenvolvimento de fármacos em Química Inorgânica Medicinal. Neste caso, para além do fármaco conter um grupo quelante, é igualmente importante que ele inclua outros grupos funcionais capazes de, dentro da cavidade/subcavidades do centro activo, estabelecer interacções ligantes com este, nomeadamente através de ligações por ponte de $\mathrm{H}$ ou interacções hidrofóbicas com resíduos de aminoácidos. Um exemplo representativo deste tipo de fármacos está ilustrado na Figura 3 com um inibidor (CGS27023A) de MMP-12.

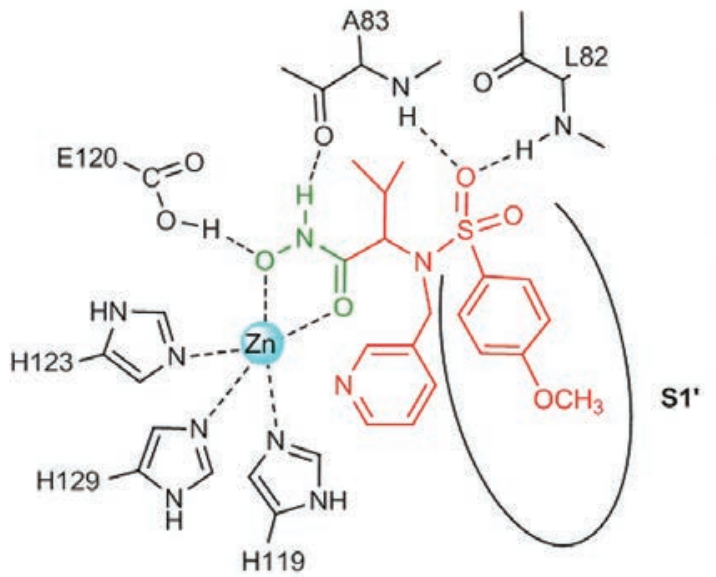

Na terapia anti-carcinogénica são também muito importantes os metalofármacos com radioisótopos de iões metálicos emissores de radiação não-penetrante $(\beta, \alpha)$ e de vida-média curta. Como dois exemplos representativos, refiram-se o complexo metálico de ${ }^{90} \mathrm{Y}$ (ítrio) com DTPA (RP762:Y(SQ169)) conjugado com um peptídeo cíclico, usado em radioterapia vectorizada para o receptor vitronectina (Figura 5 C) e o complexo de ${ }^{153} \mathrm{Sm}$ (samário) com um ligando diaminofosfonato ( ${ }^{153} \mathrm{Sm}-E D T M$, Lexidronam), usado em lesões ósseas metastáticas.

Como exemplos de outros metalofármacos com acção antiartrítica, refiram-se os complexos de ouro (Au), Aurofina, ou, ainda mais eficazes para pequenas articulações com artrite reumatoide, os complexos com radioisótopos com emissão de radiação com penetração terapêutica curta

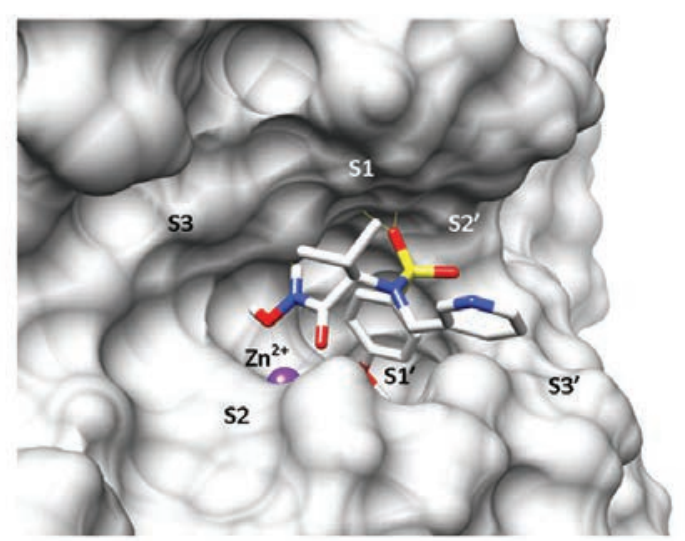

Figura 3 - Exemplo de um inibidor de metaloproteinases matriciais (MMP-12) CGS27023A (a vermelho e verde) e sua interacção com o centro activo da enzima (resíduos e modelo com topografia superficial). Estrutura cristalográfica 1JIZ do RCSB Protein Data Bank

Neste caso, o grupo quelante usado para a interacção com o cofactor de zinco da enzima é também o grupo hidroxamato, (-CONHOH), responsável pela coordenação do fármaco DFO ao ferro (Figura 2). Apesar de este ser um dos grupos quelantes mais usado e mais eficaz na inibição de MMPs, efeitos colaterais justificam que outras classes de quelantes tenham sido objecto de intensos estudos, incluindo análogos de hidroxamatos e hidroxipiridinonas (vide infra) [9,11,12].

\section{Metalofármacos}

O desenvolvimento e a aplicação de compostos contendo iões metálicos (metalofármacos) em actos clínicos terapêuticos admite-se ter começado com a descoberta ocasional (R. Rosenberg, 1960) da Cisplatina [cis-diaminodicloroplatina(II)], a qual ainda hoje é usada como agente antitumoral (testículo, ovários), sendo a sua acção maioritariamente atribuída à interacção com o DNA. Outros complexos análogos estão também em uso clínico, como a Carboplatina, com menor eficiência mas menor toxicidade, assim como metalofármacos com platinoides e outros metais [13], nomeadamente o ruténio, como no KP1019 em testes clínicos para quimioterapia tumoral [14] (Figuras 4 e 5 A).
(1 mm) e muito curta $(0,3 \mathrm{~mm})$, nomeadamente soluções coloidais de citrato de ${ }^{186} \mathrm{Re}$ (rénio) e de ${ }^{169} \mathrm{Er}$ (érbio), respectivamente [15].

O uso de metalofármacos como agentes de contraste em métodos de diagnóstico de doenças, principalmente para a detecção de tumores ou processos inflamatórios, reveste-se também de uma enorme relevância, especialmente os métodos de ressonância magnética (MR) e os métodos de Medicina Nuclear de emissão de radiação. No caso dos métodos imagiológicos com ressonância magnética (MRI), usam-se agentes de contraste baseados em complexos com iões metálicos paramagnéticos, maioritariammente complexos de Gd(III) com ligandos do tipo poliazapoliacetato (DTPA ou DOTA), muito embora complexos com outros metais, como Mn(II) com DPDP (Figura 5B) também estejam em uso clínico. De realçar que, recentemente tem-se assistido a um grande impulso na pesquisa de novos agentes de contraste de MRI, especialmente dirigida para aumentar a intensidade da imagem e a sua especificidade para órgãos e tecidos, através da bifuncionalização (vide infra), ou ainda da nanoestruturação de fármacos com possibilidade de imagiologia bimodal [16].

Nos metalofármacos para radiodiagnóstico têm sido maioritariamente usados complexos com radionuclídeos com 
emissão de radiação gama $(\gamma)$ ou com emissão de positrões. No primeiro caso inclui-se a cintigrafia ou tomografia SPECT, com os seguintes exemplos: ${ }^{99 m}$ Tc (tecnécio), Cardiolite, complexo $\left[{ }^{99 m} \mathrm{Tc}-(\mathrm{MIBI})_{6}\right]$ (MIBI = metoxi-isobutilisonitrilo) usado na imagiologia do miocárdio; ${ }^{111}$ In (índio), Octreoscan, complexo ${ }^{111}$ In-DTPA-octreótido, usado na cintigrafia de cancro do pulmão (receptores de somatostatina); complexo ${ }^{67} \mathrm{Ga}$-bis(citrato) (para imagiologia e estadiamento de alguns tumores). Na tomografia por emissão de positrões (PET), um dos métodos com maior sensibilidade na diferenciação de metástases, os metalofármacos que têm sido mais explorados são complexos de ${ }^{68} \mathrm{Ga}$ com ligandos do tipo poliazapoliacetato (DTPA ou DOTA) ou análogos bifuncionalizados [1,17-19] (Figuras 4, 5B e 5C)).
Em resumo: a larga variedade e as propriedades dos metalofármacos dependem do tipo de metal usado e do correspondente agente quelante (envelope), assim como da biomolécula alvo com a qual ele interactuará. Enquanto alguns complexos, como a Cisplatina e outros análogos que actuam por intercalação com o DNA, podem ter alguma labilidade, no caso dos radiofármacos, cuja acção se baseia no efeito de radiações emitidas pelos metais sobre proteínas ou tecidos, os respectivos complexos devem ser inertes. Esse conhecimento permite ao Químico Medicinal seleccionar o ligando mais adequado para o complexo metálico (ver Fig 5), de modo a optimizar a razão eficácia/toxicidade.

Finalmente, convém ainda recordar que a grande expansão verificada no desenvolvimento de novos metalofármacos

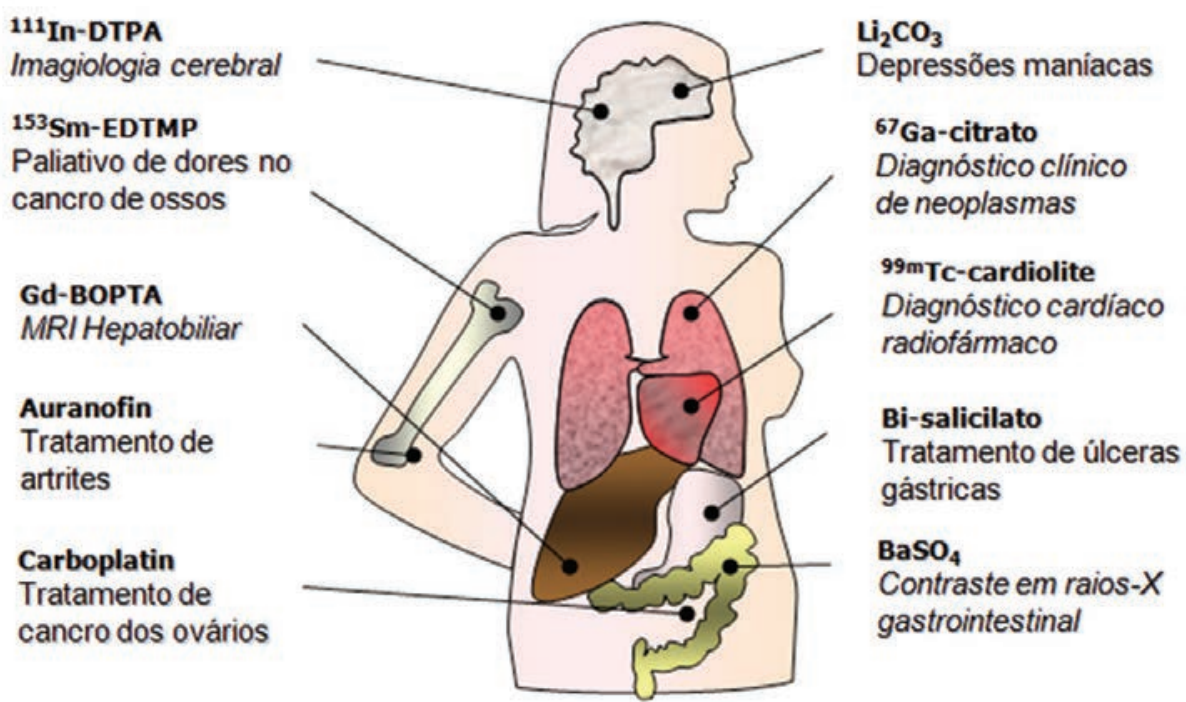

Figura 4 - Exemplos de aplicações de iões metálicos em Medicina: diagnóstico e terapia (adaptado da ref. [19])

A<smiles>N[Pb](N)Cl</smiles>

Cisplatina (PlatinolB))

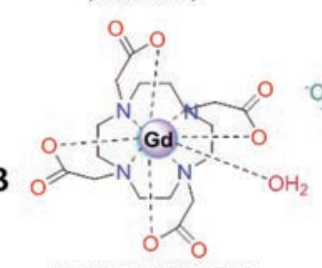
[Gd(DOTA) $\left.\left(\mathrm{H}_{2} \mathrm{O}\right)\right]$ (Dotarem $B)$

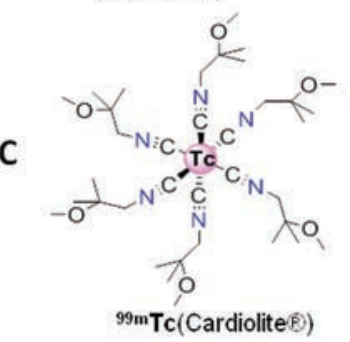

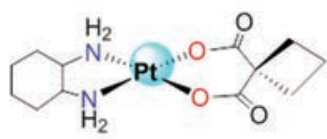

Carboplatina (Paraplatin $B)$<smiles></smiles>

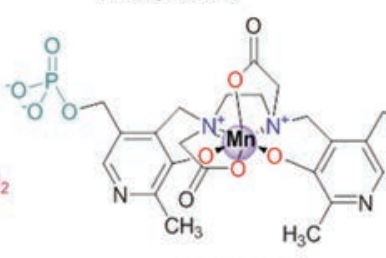

[Mn(DPDP) (Teslascan $\mathbb{B}$ )
KP109 *

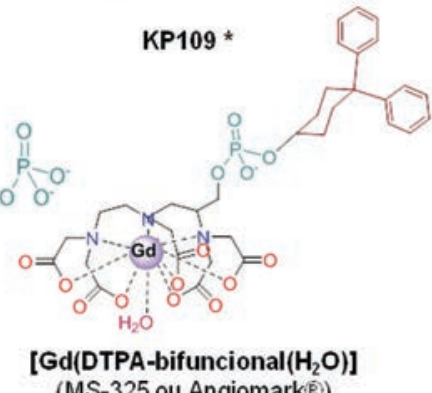

(MS-325 ou Angiomark $B$ )

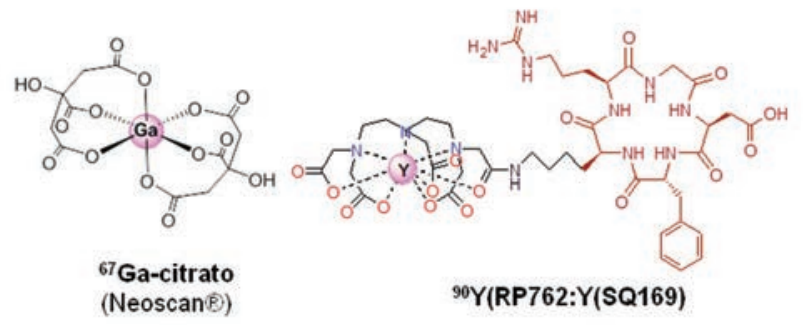

Figura 5-Alguns complexos metálicos utilizados na prática médica (*ou em testes clínicos) e correspondentes designações comerciais: (A), complexos de platina, Pt(II), e de ruténio, Ru(III), como agentes anti-tumorais; (B), complexos de gadolínio, Gd(III), e de manganês, Mn(II), como agentes de contraste em imagiologia de ressonância magnética (MRI); (C), complexos com radionuclídeos: tecnécio $\left({ }^{99 m} \mathrm{Tc}\right)$ e gálio $\left({ }^{67} \mathrm{Ga}\right)$ como agentes de radiodiagnóstico e estadiamento de tumores; irídio $\left({ }^{90} \mathrm{Y}\right)$ como agentes de radioterapia do cancro [1,17-19] 
surgiu há menos de duas décadas com a emergência dos supercomputadores e supercondutores, levando à consequente enorme evolução de equipamentos e meios de diagnóstico e terapia ou ainda, mais recentemente, da sua combinação (teranóstico).

\section{QuímICA E MODULAÇÃO dAS PROPRIEDADES DE FÁRMACOS RELACIONADOS COM METAIS}

A Química Inorgânica Medicinal é uma área multidisciplicar que combina Química Orgânica, Inorgânica, Farmacologia e Bioquímica, para além da importante contribuição da Química Computacional e da Análise Química. O desenvolvimento de novos fármacos na área da medicina de coordenação inclui, em primeiro lugar o seu design (com base em conhecimentos prévios e modelação molecular) seguido da síntese de ligandos, estudos em solução da capacidade de complexação do metal e de outras propriedades físico-químicas como a lipofilicidade e o potencial de oxi-redução. Inclui também estudos in vitro com enzimas ou outras proteínas e, subsequentemente, com células específicas para avaliação da actividade biológica e de efeitos tóxicos; para os compostos mais promissores, são ainda efectuados estudos in vivo em modelos animais para avaliar os perfis de biodistribuição e de excreção bem como a toxicidade. No caso dos metalofármacos (complexos metálicos), convém recordar que, muito embora a sua actividade biológica e acção clínica sejam determinadas pelo próprio metal, estas dependem muito do seu estado de oxidação, do tipo e número de ligandos coordenados, da força da ligação, da geometria do complexo, do potencial redox e da velocidade de permuta de ligando (labilidade do complexo).

\subsection{Parâmetros relevantes na estratéGia de design. EXEMPLOS}

A primeira opção para o design de um fármaco relacionado com metais consiste na eleição do ião metálico objectivo e, em função das suas características electrónicas/iónicas, definir o tipo de grupos quelantes ou grupos doadores de electrões (ex. - $\mathrm{RS}^{-}$, - $\mathrm{NH},-\mathrm{COO}^{-}$e $-\mathrm{O}^{-}$) que deverão ser incluídos numa determinada unidade molecular, resultando assim um agente quelante (ou ligando) com um ou vários grupos quelantes (ex., [(C=O)-NO-]; $\left[(\mathrm{C}=\mathrm{O})-\mathrm{CO}^{-}\right]$) (Figura. 3). O número de grupos quelantes necessários no ligando depende do tipo de ião, normalmente aumentando com o raio iónico, carga e grau de toxicidade deste, de modo a garantir estabilidade termodinâmica e cinética do complexo metálico nas condições fisiológicas. Existem ainda outros factores a considerar, nomeadamente relacionados com o facto de, in vivo, o fármaco administrado ter uma interacção directa metal-biomolécula, quer como ligando (ex. agentes quelação, inibidor enzimático) quer como complexo (ex. metalofármacos como intercaladores de DNA).

Para os metalofármacos com o ião paramagnético $\mathrm{Gd}^{3+}$, usados em MRI, o complexo metálico também deverá ser muito estável para garantir a sua excreção sob a forma de complexo intacto e impedir processos de transmetalação com ligandos biológicos. Contudo, a coordenação ao metal não deverá ser completa, deixando pelo menos uma posição de coordenação vaga para que pelo menos uma molécula de água se possa também ligar directamente ao ião metálico, contribuindo assim para um aumento da relaxividade do complexo e consequentemente do contraste da imagem (MRI). A Figura 5B ilustra a estrutura dos complexos de Gd(III) com DOTA e DPTA, contendo uma molécula de água coordenada, e o complexo de manganês [Mn(II)-DPDP], também usado em clínica (imagiologia de cancro do fígado), sem coordenação a moléculas de água, e cujo contraste de imagem obtido é inferior ao dos complexos de $\mathrm{Gd}(\mathrm{III})$ com coordenação a $\mathrm{H}_{2} \mathrm{O}$ [1]. Contudo, outras estratégias têm sido recentemente seguidas em pesquisas para aumentar a intensidade do sinal do contraste de MR, nomeadamente, usando outros ligandos que permitem um maior número de moléculas de água coordenadas ao metal, como as tris-hidroxipiridinonas [20,21], ou promovendo a formação de agregados moleculares, como micelas [22].

Para metalofármacos que incluem um ião metálico de elevada toxicidade, como os isótopos nucleares que são usados em radioterapia ou radiodiagnóstico, independentemente da energia/intensidade da radiação emitida e do tempo-médio de vida, deve-se sempre garantir que ele fique fortemente sequestrado. Para tal, devem-se usar grupos quelantes mais “fortes” e/ou em número suficiente para assegurar que o metal seja excretado na forma do complexo e não fique retido no corpo devido à permuta de ligandos e a complexação do ião metálico com ligandos biológicos existentes in vivo. Em alguns casos opta-se por ligandos do tipo macrocíclico que poderão possuir grupos quelantes menos fortes, mas que conseguem encapsular o ião metálico, aumentando assim a inércia química do complexo (ver Dotarem $^{\circledR}$, Figura 5-B).

Como segundo passo na estratégia de design de novos fármacos é necessário ter em conta que a sua utilidade como medicamento depende da possibilidade deste ser transportado para um determinado local de acção (orgão/tecido) numa concentração suficiente para provocar uma resposta farmacológica. Essa capacidade depende de vários factores, nomeadamente a absorção, a biodistribuição, a excreção e ainda a metabolização do fármaco, sendo os três primeiros factores bastante dependentes das características do fármaco e da sua capacidade para atravessar membranas celulares. Por outro lado, se eles têm que interactuar com biomoléculas específicas, como enzimas ou receptores biológicos, que são expressados em tumores ou locais de inflamação, é conveniente que a unidade quelante do metal (M) seja bifuncionalizada, através do seu acoplamento um outro segmento molecular que favoreça essa interacção extra (Figura 3, com inibidor de metaloenzimas). Este tipo de grupos extra-funcionais (extra-funções), poderão ainda desempenhar o papel de vectores moleculares para direccionar o fármaco para um receptor molecular específico, tecido ou órgão, aumentando assim a sua concentração junto ao local de acção (Figura 6). 


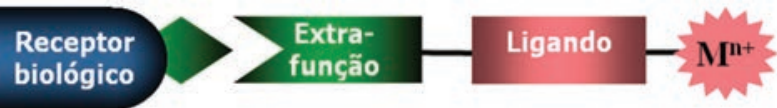

Figura 6 - Esquema da estrutura integrante de um complexo metal-ligando com grupo extra-funcional (vector molecular)

Alguns exemplos de metalofármacos bifuncionalizados estão ilustrados na Figura 5 (B e C), nomeadamente o radiofármaco ${ }^{90}$ Y-RP762 (agente anti-tumoral) e MS-325 (agente de contraste em angiografia de RM), cujas unidade quelantes (DPTA) estão extra-funcionalizadas com, respectivamente, um ciclopeptídeo como vector molecular para um receptor sobrexpresso por certo tipo de tumores, ou um grupo (difenilciclo-hexilo) capaz de se ligar à albumina do soro humano [18]. De realçar que a bifuncionalização de fármacos de diagnóstico pode ainda providenciar propriedades terapêuticas, e vice-versa, resultando daí os designados agentes "teranósticos”, com perspectivas futuras muito promissoras [23].

Uma vez identificados e definidos estes parâmetros principais, antes do início de processos experimentais dispendiosos (síntese e avaliação de propriedades físico-químicas e biológicas), poderá ainda ser importante fazer um ajuste na estrutura dos compostos a desenvolver, através de selecção de grupos substituintes ou de ligação entre os vários segmentos moleculares, Para tal, normalmente, faz-se um screening virtual, através de programas de simulação computacional (métodos de Monte Carlo, semiempíricos QM/MD, DFT e docking), para antecipar a estabilidade do complexo metálico e/ou a actividade do fármaco baseada na sua capacidade de interacção com biomoléculas específicas. A antecipação de descritores moleculares, determinantes para as propriedades farmacocinéticas dos candidatos a fármaco, poderá também ser obtida por métodos computacionais. Concretamente, pode-se antecipar dados indicadores da biodisponibilidade oral de um potencial fármaco (evitando violações às regras de Lipinsky) assim como da sua capacidade de atravessar certo tipo de membranas biológicas e de ser transportada para locais específicos de acção.

\section{DesenVolvimentos RECENTES EM CANDIDATOS A FÁRMA- COS RELACIONADOS COM METAIS. EXEMPLOS}

Nesta secção apresentaremos alguns exemplos recentes de novos desenvolvimentos que têm sido feitos pelo nosso e outros grupos de investigação na área da Química Inorgânica Medicinal, cuja potencial acção farmacológica resulta ou dos próprios ligandos (que interagem ou sequestram iões metálicos de organismos ou do ambiente) ou dos correspondentes complexos (metalofármacos). Apesar de no nosso grupo terem sido recentemente desenvolvidos inúmeros compostos contendo diferentes grupos quelantes (ex. hidroxamato, hidroxipiridinona, hidroxipirona, hidroxipirimidinona), nos exemplos seleccionados, e a seguir brevemente descritos, optou-se por incluir apenas alguns desenvolvimentos feitos com ligandos/complexos contendo grupos quelantes do tipo hidroxipiridinona, análogos da desferriprona (DFP) (Figura 2).
No desenvolvimento de novos compostos reconhecem-se certas classes de moléculas que, por serem fáceis de obter (funcionalizar e manipular) a partir de compostos existentes na natureza, e por serem muito estáveis e não degradáveis, para além de existirem já em vários fármacos, podem ser consideradas como estruturas "privilegiadas” para o design racional de fármacos [9]. Tal é o caso dos derivados do tipo hidroxipiridinona (HP), heterociclos com grupos quelantes $\alpha$-hidroxicarbonilo, em especial a classe das 3-hidroxi-4-piridinonas (3,4-HP) a que pertence a desferriprona (DFP). A sua potencial utilização tem sido direccionada não só para sequestração e terapia de sobrecarga de Fe(III) (ex DFP, Figura 2) e outros iões metálicos duros (ex: Al(III), Pu(IV)), mas também para o tratamento de outros processos patológicos cuja privação do ferro é determinante na cura, como as doenças neurodegenerativas (doenças de Alzheimer e de Parkinson), certos tipos de cancro e ainda infecções microbiológicas (antibacteriana e antimalária). Este tipo de ligandos tem também sido envolvido numa nova geração de metalofármacos (Figura 7) que ainda se encontra em fase de ensaios pré-clínicos (modelos com animais).

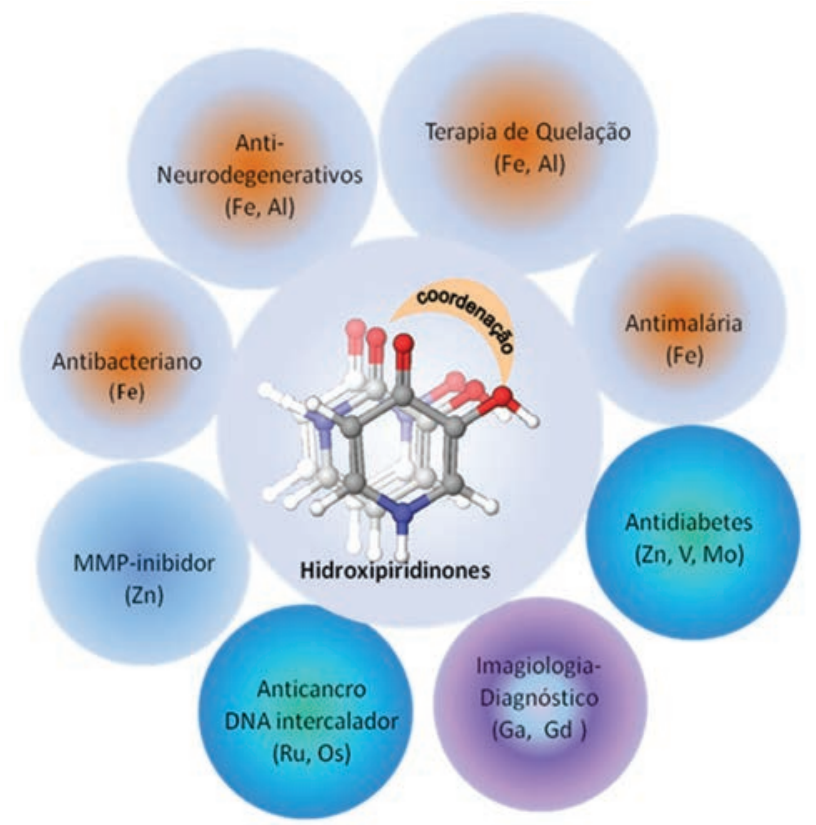

Figura 7 - Exemplos de aplicações de hidroxipiridinonas como estruturas “privilegiadas” no design de fármacos com quelantes (adaptado da ref. [9])

\subsection{3,4-HPS COMO AGENTES QUELANTES OU INIBIDORES DE ME- TALOENZIMAS}

No design e exploração deste tipo de compostos como potenciais fármacos usaram-se normalmente três tipos de estratégias básicas a seguir sumarizadas:

A) A poli-quelação, em que cada entidade molecular inclui dois ou três grupos quelantes (3,4-HP), ou ainda vários destes grupos “agrafados” a matrizes sólidas, com vista a assegurar uma forte sequestração para uso como depuradores de certos iões metálicos (ex. Fe, Al, actinídeos) do corpo humano ou fluidos corporais [5,7,24,25], ou ainda como agentes anti-microbianos (Fe) [26]. 
B) A extra-funcionalização da unidade quelante que, no caso da terapia de quelação, pode ter em vista uma diferenciação na biodistribuição do agente quelante, conforme os órgãos em situação patológica de excesso de metal; alternativamente, a bifuncionalização tem em vista o estabelecimento de interacções com outros resíduos nas cavidades dos centros activos de enzimas de zinco (ex. MMP, HDAC), melhorando assim a actividade inibitória dos compostos [11,12,27].

C) A bifuncionalização da unidade quelante pode ainda permitir atingir outros alvos terapêuticos em doenças complexas. Com efeito, em cérebros de pacientes com doenças neurodegenerativas, como a doença de Alzheimer (AD) e a doença de Parkinson (PD), além da necessidade de correcção da des-homeostase do ferro, responsável pelo elevado stresse oxidativo, outros alvos terapêuticos importantes podem também ser modulados, como a inibição das enzimas AChE e MAO-B, responsáveis pela destruição de neurotransmissores importantes como a acetilcolina e a dopamina, respectivamente. Há ainda a considerar a inibi- ção de formação da placa amiloide em pacientes com AD e o combate do stresse oxidativo (anti-oxidação) por sequestração de radicais livres [27-29]. Com esta estratégia espera-se obter fármacos multi-funcionais com reconhecidas vantagens sobre o uso de protocolos complexos com administração de vários fármacos mono-funcionais [31].

\subsection{3,4-HPS COMO POTENCIAIS METALOFÁRMACOS}

Como exemplo representativo de novos potenciais candidatos a metalofármacos, contendo unidades quelantes do tipo HP, refira-se um complexo de zinco(II) com duas unidades quelantes, análogos tio-carbonilo de HP (TioHP, X = S)). Este complexo, embora por um mecanismo ainda não estabelecido, pensa-se que consegue simular a acção da insulina, promovendo a resposta de receptores da membrana celular que permitem a abertura de canais para a entrada da glucose nas células, através de um efeito designado de insulino-mimético [32] (Figura 8). Existem estudos idênticos de outros análogos oxo-derivados com Zn(II) e outros iões metálicos, mas com menor actividade.

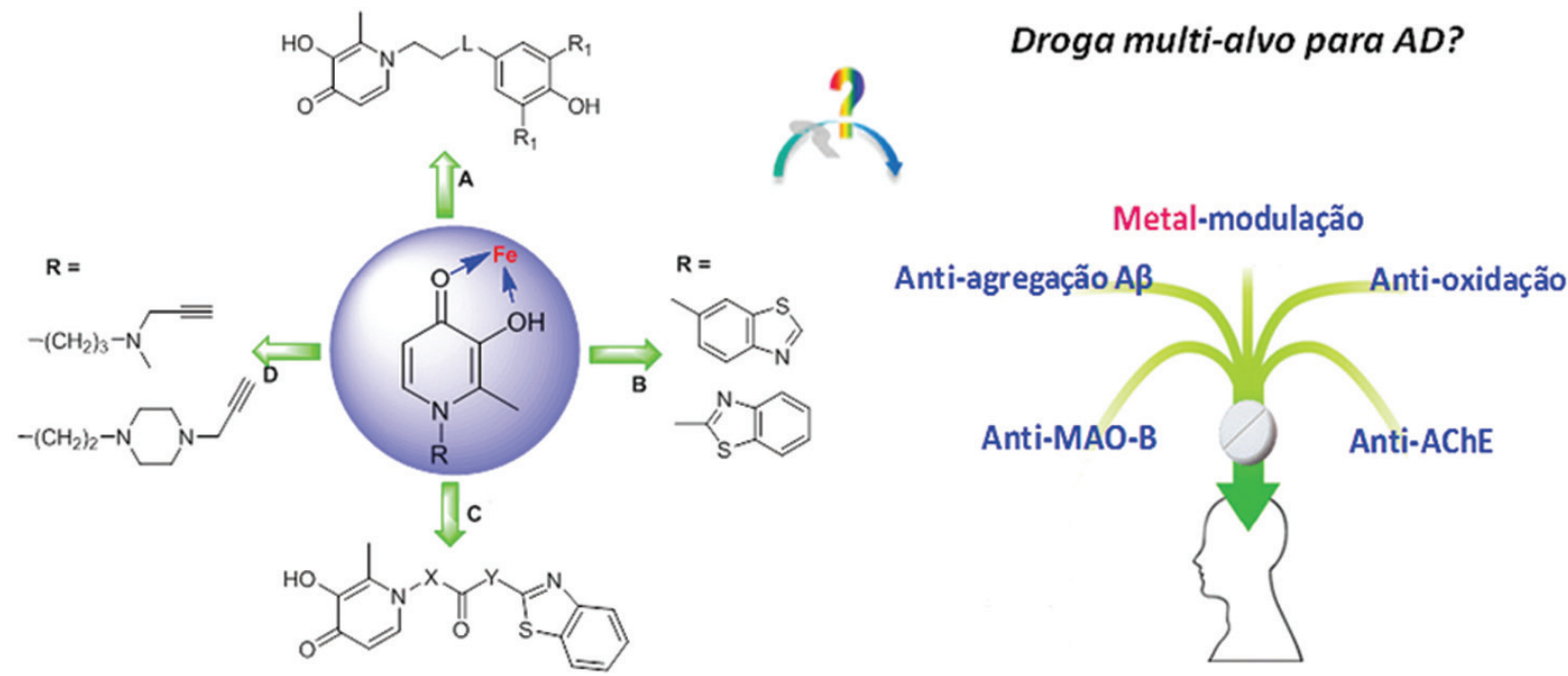

Figura 8 - Exemplos de compostos híbridos ou polifuncionais, em que uma unidade quelante (3,4-HP) é conjugada com outros grupos funcionais com propriedades anti-neurodegenerativas: anti-oxidação (A); anti-agregação da $\beta$-amiloide (B); anti-AChE e anti-agregação da $\beta$-amiloide (C); antiMAO-B (D)

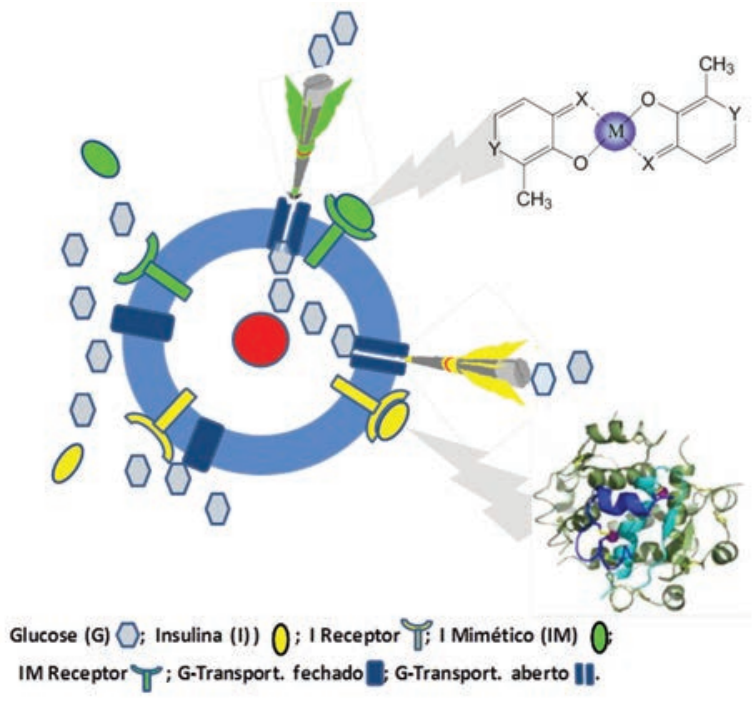

Um segundo exemplo de um potencial metalofármaco com unidades quelantes do tipo HP está representado na Figura 10. Esta inclui o modelo da estrutura de um complexo de gálio com um agente quelante tripodal com três "garras" ligadas a um átomo “âncora” central (Tris-HP). A elevada estabilidade termodinâmica do complexo garante que o ião metálico não se dissocia do ligando [33]. Este facto é muito importante tendo em vista a aplicação potencial como agente de imagem nuclear (PET) com o radionuclídeo ${ }^{68} \mathrm{Ga}$. Nesta figura estão ainda representados o perfil de biodistribuição e a imagem cintigráfica dum ratinho ao qual foi administrado um complexo com ${ }^{67} \mathrm{Ga}$, evidenciando que o potencial radiofármaco deverá ter um perfil de excreção rápida por via renal.
Figura 9 - Estrutura de um potencial metalofármaco [Zn-(TioHP) $)_{2}(\mathrm{X}=\mathrm{S}$, $\mathrm{Y}=\mathrm{O}$ ) e acção insulino-mimética proposta 


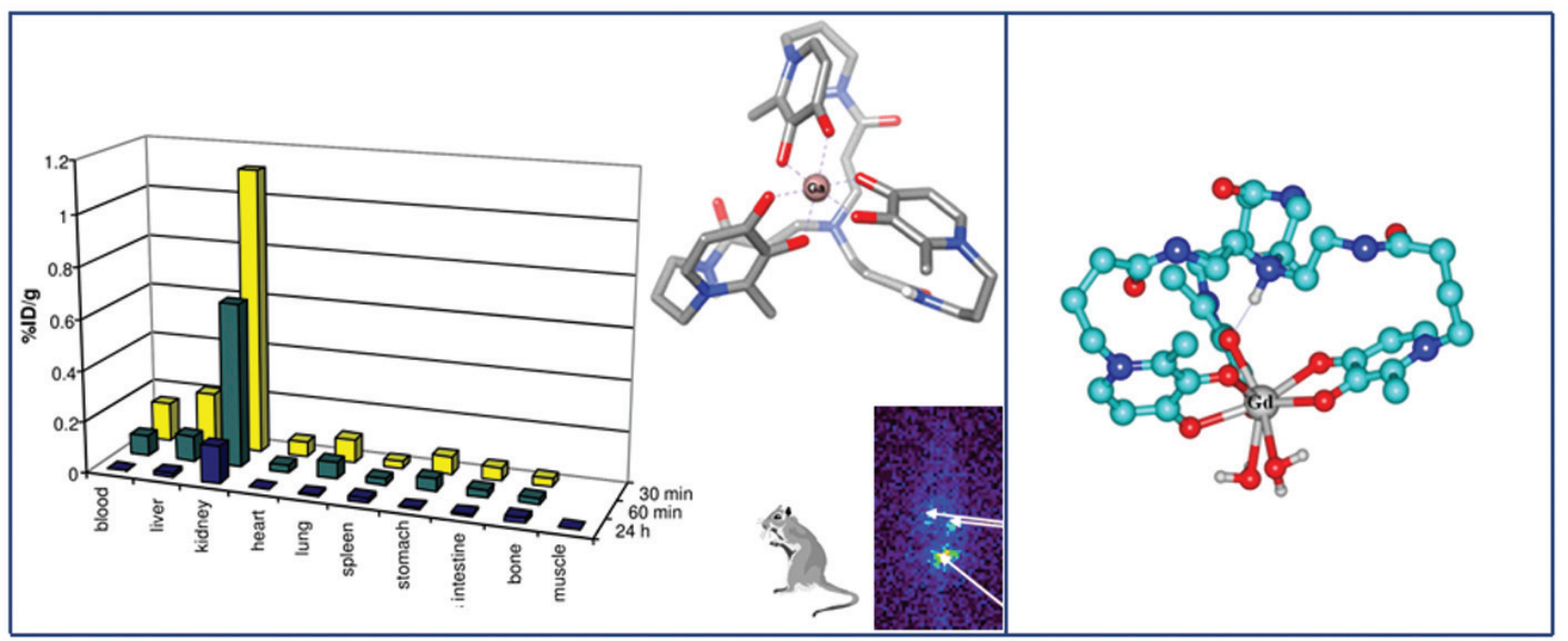

Figura 10 - A) Modelo da estrutura do complexo [Ga-(Tris-HP)]. Perfil de biodistribuição e cintigrafia do ratinho após administração do correspondente complexo de ${ }^{67} \mathrm{Ga}$ (adaptado da ref [33]). B) Modelo de complexo [Gd-Tris $\mathrm{HP}\left(\mathrm{H}_{2} \mathrm{O}\right)_{2}$ ]

O complexo análogo de Gd(III) (Figura 10 B) evidenciou elevada estabilidade, apesar de conter duas moléculas de água coordenadas, com perfis de RM (relaxividade) muito promissores [21]. Os estudos em curso de bifuncionalização deste tipo de complexos poderão permitir ajustar a especificidade da biodistribuição, com vista à potencial aplicação desta família de compostos em imagiologia com PET ou MRI.

\section{Perspectivas futuras}

A aplicação da Química Inorgânica à Biologia e à Medicina permite melhorar a nossa compreensão sobre aspectos moleculares associados a certas doenças e obter novas ideias e estratégias para o design de novos agentes de terapia ou de diagnóstico. Existem muitos fármacos cuja acção está relacionada com metais essenciais e não essenciais existentes na Tabela Periódica de elementos, para além de inúmeros radioisótopos com aplicação em Medicina Nuclear. A química e a bioquímica das interacções destes iões metálicos com ligandos e com potenciais biomoléculas objectivo, tais como o DNA e certas proteínas, constitui uma base determinante para o desenvolvimento racional de novos metalofármacos mais eficazes e com maior capacidade de atingir alvos preferenciais, como órgãos, tecidos e biomoléculas associados a um processo patológico. Na projecção desta perspectiva no futuro é muito importante a contribuição de ramos da ciência mais recentes como a bioinformática, para antecipar a acção do fármaco a nível molecular/funcional e farmacocinético. Por outro lado, sendo a optimização de mecanismos de transporte e de controlo da acção do fármaco fundamental para a sua eficácia, neste campo, as novas nanotecnologias têm e terão um papel fundamental em futuros desenvolvimentos.

É de realçar que qualquer composto candidato a fármaco tem ainda um caminho bastante longo a percorrer, começando por testes in vivo (animais) para avaliar a biodistribuição, a absorção oral, a metabolização e efeitos tóxicos laterais. Muito embora os perfis do fármaco em animais sejam muitas vezes semelhantes, aos observados no Homem, têm ainda de ser efectuados testes com voluntários humanos antes de se passar à fase clínica.

\section{REFERÊNCIAS}

[1] Z. Guo, P.J. Sadler, Angew. Chem. Int. Ed. 38 (1999) 1512$-1531$

[2] a) J.J.R. Fraústo da Silva, R.J.P. Williams, “The Biological Chemistry of the Elements”, Oxford University Press, Oxford, 1991; b) J. J. R. Fraústo da Silva, "Introdução à Química da Vida”, UNL, 1985

[3] A. Pitrangelo, New Engl. J. Med. Chem. 350 (2004) 2383$-2397$

[4] G. Crisponi, M. Remelli, Coord. Chem. Rev. 252 (2008) $1225-1240$

[5] M.A. Santos, Coord. Chem. Rev. 252 (2008) 1213-1224

[6] Y. Ma, T. Zhou, X. Kong, R.C. Hider, Curr. Med. Chem. 19 (2012) 2816-2827

[7] M.A. Santos, M.A. Esteves, S. Chaves, Curr. Med. Chem. 19 (2012) 2773-2793

[8] L.E. Scott, C. Orvig, Chem. Rev. 109 (2009) 4885-4910

[9] M.A. Santos, S.M. Marques, S. Chaves, Coord. Chem. Rev. 256 (2012) 240-259

[10] a) S.M. Marques, E. Nuti, A. Rossello, C.T. Supuran, T. Tuccinardi, A. Martinelli, M.A. Santos, J. Med. Chem. 51 (2008) 7968-7979; b) C.T. Supuran, Drug Devel. Res. 69 (2008) 297-303

[11] A. Agrawal, D. Romero-Perez, J.A. Jacobsen, F.J. Villarreal, S.M. Cohen, ChemMedChem 3 (2008) 812-820

[12] S.M. Marques, T. Tuccinardi, A. Martinelli, S. Santamaria, E. Nuti, A. Rossello, V. André, M.A. Santos., J. Med.Chem. 54 (2011) 8289-8298

[13] M.J. Clarke, F. Zhu, D.R. Frasca, Chem. Rev. 99 (1999) 2511-2534

[14] C.G. Hartinger, M.A. Jakupec, S. Zorbas-Seifried, M. Groessl, A. Egger, W. Berger, H. Zorbas, P.J. Dyson, B. K. Keppler, Chem. Biodivers. 5 (2008) 2140-2155 
[15] J. Coya-Vina, M. Main-Ferrer, L.M. Matin-Curto, "Radioactive Isotopes for Radiosynoviorthesis”, Chap 11, pag. 68-71, em The Haemophilic Joints, Edit E.C. RodriguezMerchan, Blackwell Publ. Ltd (2003)

[16] S.L.C. Pinho, H. Faneca, C.F.G.C. Geraldes, J. Rocha, L.D. Carlos, M.-H. Delville, Eur. J. Inorg. Chem. (2012) 28282837

[17] F. Roesch, P.J. Riss, Curr. Top. Med. Chem. 10 (2010) 1633-1668

[18] a) S. Liu, D.S. Edwards, Bioconjugate Chem. 12 (2001) 7-34; b) H.R. Maecke, J.C. Reubi, J. Nucl. Chem. 52 (2011) 841-844

[19] K. Thompson, C. Orvig, Science 300 (2003) 936-939

[20] E.J. Werner, A. Datta, C.J. Jocher, K.N. Raymond, Angew. Chem. Int. Ed. 47 (2008) 8568-8580

[21] A.C. Mendonça, A.F. Martins, A. Melchior, S.M. Marques, S. Chaves, S. Villette, S. Petoud, P.L. Zanonato, M. Tolazzi,C.S. Bonnet, É. Tóth, P. Di Bernardo, C.F.G.C. Geraldes, M.A. Santos, Dalton Trans. 42 (2013) 6046-6057

[22] A. Sá, C.S. Bonnet, C.F.G.C. Geraldes, É. Tóth, P.M.T. Ferreira, J.P. André, Dalton Trans. 42 (2013) 4522-4532

[23] a) H.-K. Kim, M.-K. Kang, K.-H. Jung, S.-H. Kang, Y.-H. Kim, J.-C. Jung, G. H. Lee, Y. Chang, T.-J. Kim, J. Med. Chem. 56 (2013) 8104-8111; b) D. Can, B. Spinger, P. Schmutz, F. Mendes, P. Raposinho, C. Fernandes, F. Carta, A. Innocenti, I. Santos, C.T. Supuran, R. Alberto, Angew. Chem. Int. Ed. 51 (2012) 3354-3357
[24] S. Chaves, S.M. Marques, A.M.F. Matos, A. Nunes, L. Gano, T. Tuccinardo, A. Martinelli, M.A. Santos; Chem. Eur. J. 16 (2010) 10535-10545

[25] R. Grazina, M.A. Santos, J. Hazard. Mat. 186 (2011) 1902$-1908$

[26] S.S. Fernandes, A. Nunes, A.R. Gomes, B. de Castro, R.C. Hider, M. Rangel, R. Appelberg, M.S. Gomes, Microbes and Infection 12 (2010) 287-294

[27] M.A. Santos, M. Gil, L. Gano, S. Chaves, J. Biol. Inorg. Chem. 10 (2005) 564-580

[28] D. Arduíno, D. Silva, S.M. Cardoso, S. Chaves, C.R. Oliveira, M.A. Santos, Frontiers in Bioscience 13 (2008) 6763-6774

[29] A. Nunes, S.M. Marques, C. Quintanova, D.F. Silva, S.M. Cardoso, S. Chaves, M.A. Santos, Dalton Trans. 42 (2013) 6058-6073

[30] C. Rodríguez-Rodríguez, M. Telpoukhovskaia, C. Orvig, Coord. Chem. Rev. 256 (2012) 2308-2332

[31] R. Morphy, R. Rankovic, Curr. Pharm. Des. 15 (2009) 587$-600$

[32] S. Chaves, R. Jelic, A.C. Mendonça, M. Carrasco, Y. Yoshikawa, H. Sakurai, M.A. Santos, Metallomics 2 (2010) 220-227

[33] S. Chaves, A.C. Mendonca, S.M. Marques, M.I. Prata, A.C. Santos, A.F. Martins, C.F.G.C. Geraldes, M.A. Santos, J. Inorg. Biochem. 105 (2011) 31-38

\section{Actualidades Científicas}

\section{NOVOS MATERIAIS COM POTENCIAL APLICAÇÃO EM BIOMEDICINA}

Os bisfosfonatos são um grupo de compostos utilizados como fármacos para o tratamento de doenças ósseas como a osteoporose. Alanne et al. (2013) apresentaram um estudo sobre uma nova aplicação de bisfosfonatos: a sua capacidade de formar géis em água.

Este estudo permitiu um melhor conhecimento dos factores que afectam os processos que conduzem à gelificação, podendo dar origem a novos materiais para aplicações inovadoras em biomedicina. Estes materiais podem, por exemplo, ser úteis como substitutos na recuperação, manutenção e/ou melhoria da função do tecido ósseo. Além disso podem actuar como plataformas para mimetizar a matriz extracelular e fornecer suporte para a adesão, migração e proliferação celular.

Os hidrogéis tradicionais consistem em polímeros naturais e sintéticos, contudo, a capacidade de self-assembling dos bisfosfonatos (moléculas de baixo peso molecular, MBPM), originando géis supramoleculares, despertou o interesse por estes compostos. Estes géis são reversíveis e biodegradáveis o que os torna adequados para aplicações biológicas. A formação de géis supramoleculares de MBPM é devida a interacções não covalentes, tais como ligações de hidrogénio, interacções de van der Waals, de empilhamento $\pi-\pi$ e efeitos solvofóbicos.

Os géis supramoleculares diferem dos géis poliméricos tradicionais irreversíveis, porque quando submetidos a um estímulo, por exemplo aquecimento, respondem alterando a sua forma e após o termo do estímulo retomam a forma inicial.

Os géis supramoleculares apresentam várias aplicações em química de materiais e optoelectrónica. Além disso, os biomateriais baseados nestes géis podem também ser usados como agentes de biodistribuição específica de fármacos e em medicina regenerativa.

(adaptado de http://www.sciencedaily.com/releases/2013/11/131121111802.htm, acedido em 20-02-2014, e de A.L Alanne et al., J. Mater. Chem. B. 1 (2013) 6201-6212)

António Mendonça (mendonca@ubi.pt) 